\title{
AMP Deaminase 1 Gene Polymorphism and Heart Disease- A Genetic Association That Highlights New Treatment
}

\author{
Ryszard T. Smolenski • Iwona Rybakowska • Jacek Turyn • Pawel Romaszko • \\ Magdalena Zabielska • Anne Taegtmeyer • Ewa M. Słomińska • Krystian K. Kaletha • \\ Paul J. R. Barton
}

Published online: 16 January 2014

(C) The Author(s) 2014. This article is published with open access at Springerlink.com

\begin{abstract}
Nucleotide metabolism and signalling is directly linked to myocardial function. Therefore analysis how diversity of genes coding nucleotide metabolism related proteins affects clinical progress of heart disease could provide valuable information for development of new treatments. Several studies identified that polymorphism of AMP deaminase 1 gene (AMPD1), in particular the common C34T variant of this gene was found to benefit patients with heart failure and ischemic heart disease. However, these findings were inconsistent in subsequent studies. This prompted our detailed analysis of heart transplant recipients that revealed diverse effect: improved early postoperative cardiac function associated with C34T mutation in donors, but worse 1-year survival. Our other studies on the metabolic impact of AMPD1 C34T mutation revealed decrease in AMPD activity, increased production of adenosine and deinhibition of AMP regulated protein kinase. Thus, genetic, clinical and biochemical studies revealed that while long term attenuation of AMPD activity could be deleterious, transient inhibition of AMPD activity before acute cardiac injury is protective. We suggest therefore that pharmacological
\end{abstract}

R. T. Smolenski $(\bowtie) \cdot J$. Turyn · P. Romaszko $\cdot$ M. Zabielska

E. M. Słomińska

Department of Biochemistry, Medical University of Gdansk, Debinki

1, 80-211 Gdansk, Poland

e-mail: rt.smolenski@gumed.edu.pl

I. Rybakowska $\cdot$ K. K. Kaletha

Department of Biochemistry and Clinical Physiology, Medical

University of Gdansk, Debinki 1, 80-211 Gdansk, Poland

\section{A. Taegtmeyer}

Department of Clinical Pharmacology and Toxicology, University

Hospital, Zurich, Switzerland

\section{P. J. R. Barton}

NIHR Cardiovascular Biomedical Research Unit, Royal Brompton and Harefield NHS Foundation Trust, Sydney Street, London SW3 6NP, UK inhibition of AMP deaminase before transient ischemic event such as during ischemic heart disease or cardiac surgery could provide therapeutic benefit.

Keywords AMP deaminase $\cdot$ Nucleotides $\cdot$ Ischemic heart disease $\cdot$ Heart failure $\cdot$ AMP regulated protein kinase $\cdot$ Genetic polymorphism

\section{Genetic Analysis of AMP Deaminase Mutations in Humans and its Impact in Heart Disease}

A genetic background to the diversity seen in the clinical progression of heart disease is well documented. Genetic variants that lead to halted or delayed disease progression are particularly interesting as they may provide a basis for new therapies. Genetic diversity in pathways involving nucleotide metabolism are particularly important due to the latter's direct links to myocardial function and metabolic regulation [1]. Several polymorphisms of the AMP deaminase 1 (AMPDI) gene have been described [2]. The C34T (Glu12Stop) mutation in exon 2 is by far the most common in the general population with an allele frequency of 10-14\% [3]. Loh et al. [4] were the first to describe a benefit of the C34T mutation in patients with heart disease. This study conducted in a group of 132 patients with dilated cardiomyopathy demonstrated that the probability of surviving without transplantation for more than 5 years is 8.6 times greater in patients carrying the $\mathrm{C} 34 \mathrm{~T}$ allele. Anderson et al. [5] confirmed a protective effect in ischemic heart disease demonstrating prolonged survival associated with the C34T mutation in a prospective study in 450 patients. Another study by Gastmann et al. [6] conducted in a group of 90 patients with congestive heart failure demonstrated better prognosis in patients possessing the C34T AMPD1 mutation. Analysis of a consecutive group of 390 patients with left ventricular dysfunction revealed better survival in $\mathrm{C} 34 \mathrm{~T}$ allele carrier patients 
within a subgroup with ischemic cardiac dysfunction [7]. Other independent studies demonstrated a beneficial effect of the C34T mutation on metabolic aspects related to the cardiovascular system such as a lower level of an inhibitor of plasminogen activator and soluble von Willebrand factor in patients with coronary heart disease [8]. In contrast, three studies have indicated a lack or even a deleterious effect of the C34T AMPD1 mutation in patients with heart disease. A large population study conducted in 935 post myocardial infarction and 433 heart failure patients with long term follow-up indicated increased mortality associated with the $\mathrm{C} 34 \mathrm{~T}$ mutation within patients with a history of myocardial infarction [9]. A prospective study in 686 patients with stable congestive heart failure did not demonstrate any impact of the C34T polymorphism on tested clinical, biochemical, echocardiographic, radionuclide or exercise parameters [10]. Analysis of 161 patients undergoing coronary revascularisation for clinical parameters including heart failure and cardiac death revealed lack of any impact of the C34T mutation [11]. In case of C34T polymorphism, assessment of impact on cardiovascular system could be complicated because this mutation was found to exert deleterious effects on muscle performance [12]. An interesting observation was highlighted by Safranow et al. that analysed 97 patients with coronary artery disease and 104 patients with heart failure [2]. Frequency of diabetes and obesity was lower in subjects with C34T mutation (Table 1).

Our own studies have focused on the effects of the C34T mutation in patients undergoing cardiac surgery, including transplantation. We demonstrated a remarkably high frequency of C34T mutation of AMPD1 in 22 cardiac donors with good cardiac function as compared to 10 donors with echocardiographically confirmed acute cardiac failure [13, 14]. Donors with healthy hearts had a significantly higher frequency of C34T mutation also compared to control population $(n=207)$. Our recent analysis of 262 cardiac donors and 190 heart transplant recipients [15] highlighted a potential explanation for the discrepancy of published results by indicating that the $\mathrm{C} 34 \mathrm{~T}$ mutation induces diverse effects. While a protective effect was demonstrated in donor hearts with the C34T mutation in that they required less inotropic support, recipients of $\mathrm{C} 34 \mathrm{~T}$ allele carrying organs had a poorer 1 year survival. It seems that $\mathrm{C} 34 \mathrm{~T}$ mutation is protective for donor organ function in the short term but deleterious in the long term possibly due to the highly immunogenic post transplant environment. Consistent with this report we found that among a group of 153 patients undergoing coronary bypass surgery with use of cardiopulmonary bypass $\mathrm{C} 34 \mathrm{~T}$ carriers were better protected from functional deterioration [16]. In a group of patients without heart failure and with advanced coronary artery disease postoperative ejection fraction was similar to preoperative in patients with the $\mathrm{C} 34 \mathrm{~T}$ mutation while it was significantly decreased in patients without this mutation.

The C34T mutation of AMPD1 affects not only the heart system. Long before its cardiovascular associations were observed, the C34T mutation was identified as cause of skeletal myopathy $[17,18]$. Homozygotes for this mutation could have complete loss of AMP deaminase activity in skeletal muscle. It has been described as one of the most common inherited metabolic defects, with an estimated allele frequency of $20 \%$. Clinical symptoms associated with this deficiency are highly variable. While many subjects are asymptomatic others suffer from early fatigue, cramps and/or myalgia. Inability to
Table 1 Summary of clinical effects of C34T mutation of AMP deaminase in heart disease

\begin{tabular}{|c|c|c|c|}
\hline $\begin{array}{l}\text { Number of } \\
\text { patients }\end{array}$ & Diagnosis & Effect of C34T mutation & Reference \\
\hline 132 & dilated cardiomyopathy & improved survival & {$[4]$} \\
\hline 450 & ischemic heart disease & improved survival & {$[5]$} \\
\hline 90 & congestive heart failure & better prognosis & {$[6]$} \\
\hline 390 & left ventricular dysfunction & $\begin{array}{l}\text { better survival in ischemic } \\
\text { cardiac dysfunction group }\end{array}$ & {$[7]$} \\
\hline 109 & coronary artery disease & $\begin{array}{l}\text { lower level of inflammation/ } \\
\text { thrombosis markers }\end{array}$ & {$[8]$} \\
\hline 1368 & myocardial infarction or heart failure & $\begin{array}{l}\text { increased mortality in subgroup } \\
\text { with prior myocardial } \\
\text { infarction }\end{array}$ & [9] \\
\hline 686 & stable congestive heart failure & no effect & {$[10]$} \\
\hline 161 & coronary revascularisation & no effect & {$[11]$} \\
\hline 32 & heart transplantation & $\begin{array}{l}\text { high frequency in donors with good } \\
\text { cardiac function }\end{array}$ & {$[13,14]$} \\
\hline 262 & heart transplantation & $\begin{array}{l}\text { lower need for postoperative } \\
\text { inotropic } \\
\text { support, worse } 1 \text { year survival }\end{array}$ & {$[15]$} \\
\hline 201 & $\begin{array}{l}\text { coronary artery disease or heart } \\
\text { failure }\end{array}$ & lower prevalence of diabetes & {$[2]$} \\
\hline
\end{tabular}


maintain energy equilibrium, depletion of the muscle nucleotide pool or insufficient supply of anaplerotic substrates for the Krebs cycle in the exercising skeletal muscle were proposed as the underlying mechanisms of this syndrome. A varying effect of this mutation is known to be caused by alternative splicing of the AMPD1 gene involving the elimination of the C34T nonsense mutation in exon 2 and allowing production of functional enzyme $[17,19]$.

Taken together these data suggest that the C34T mutation of AMPD1 has diverse effects on the cardiovascular system and on the function of the human organism as a whole. During acute cardiovascular incidents it is clearly beneficial, but in the long term and in highly immunogenic environments such as after transplantation, the C34T mutation may have deleterious effect. Discrepancies between different studies attempting to clarify the impact of this alteration on human longevity may be a consequence of a different interplay of beneficial and deleterious effects in specific clinical conditions and under specific treatment. Besides basic information these studies have provided a clear indication when and how a potential therapy based on AMPD inhibition could be applied clinically.

\section{AMP Deaminase Isoforms and its Expression Pattern in the Heart}

AMP-deaminase (AMPD) exists in human tissues in several isoforms with different kinetic properties, molecular weights and structures. These isoforms are the products of three different genes: $A M P D 1, A M P D 2$ and $A M P D 3$. In humans $A M P D 1$ is predominantly expressed in skeletal muscle, $A M P D 2$ is predominantly expressed in the brain, liver and heart and $A M P D 3$ is expressed mainly in the erythrocytes. In rodents the expression pattern of these three isoforms is different. While $A M P D 1$ is still the dominant skeletal muscle isoform and $A M P D 2$ is present in the liver, $A M P D 3$ is almost exclusively expressed in the heart [20]. This indicates that altered expression of AMPD1 (as conferred by the C34T mutation) would not have any effect on AMPD expression in the mouse or rat heart. In humans the situation is very complex. While $A M P D 2$ is the main form expressed in human myocardium, transcripts for $A M P D 3$ and $A M P D 1$ are also present (our unpublished observations). Therefore the AMPD1 C34T mutation has an impact not only on skeletal muscle AMPD activity but also on its activity in myocardium where it causes a substantial reduction in enzyme activity even among heterozygotes [21, 22].

\section{AMP Deaminase Metabolic Function}

AMP deaminase is an enzyme involved in the breakdown of nucleotides. It has several unique cellular functions and its activity and expression pattern are highly tissue specific. It plays a particularly important role in the breakdown of nucleotides in skeletal muscle. AMP deaminase forms part of the purine nucleotide cycle, which is designed to preserve adenylate's energy charge and phosphorylation potential under conditions of insufficient energy supply. This cycle plays a crucial role in regulating the adenine nucleotide pool, in the synthesis of guanine nucleotides and in the provision of anaplerotic substrates for the Krebs cycle. These processes are important in skeletal muscle so the activity of AMP deaminase is 30-100 times higher than in the other organs. Under conditions of heavy exercise, when AMP accumulates, AMP deaminase allows rapid breakdown of AMP to IMP allowing a higher value of phosphorylation potential and free energy from ATP hydrolysis that translates directly into improved exercise capacity to be maintained. After exercise, when energy use is decreased, the IMP (a polar molecule) that remained inside the cell is reincorporated back into the adenine nucleotide pool via the adenylosuccinate synthetase and adenylosuccinate lyase reactions. The latter reaction also releases fumarate that supports the operation of the Krebs cycle.

In the heart and non-muscle organs AMP deaminase is not involved in the purine nucleotide cycle, but plays a role in regulation of the adenine nucleotide pool and in the synthesis of guanine nucleotides. The contribution of the AMP deamination pathway to the overall catabolism of nucleotides seems to be lower in human cardiomyocytes than in rat cardiomyocytes [23, 24], but still accounts for $30 \%$ of the total breakdown capacity.

\section{Increased Production of Adenosine due to AMP Deaminase Deficiency}

An important consequence of AMP deaminase deficiency is an increased flux of substrates through the 5'-nucleotidase pathway and increased adenosine production under conditions of heavy exercise. Adenosine content was found to increase 14 times in skeletal muscle biopsies taken from patients with AMPD deficiency during exercise compared with a 2 fold increase in normal subjects $[25,26]$. The physiological effects of increased adenosine production in this setting have not been evaluated. However, previous studies have shown that increased production of adenosine may ameliorate a number of pathological processes including those involved in heart failure [27]. Adenosine has long been recognised to increase coronary flow and to be involved in the autoregulatory loop between contractile cells and blood supply [28] and was classified as an autacoid, retaliating against external stimuli, which deplete intracellular ATP in the heart [29]. A number of other cardioprotective physiological effects of adenosine have been described, such as the antagonism of catecholamine mediated hypercontraction, an anti-aggregatory activity, the 
inhibition of adhesion and toxic free radical generation by polymorphonuclear leukocytes, the promotion of angiogenesis and the induction of preconditioning [30-34]. Adenosine inhibits $\mathrm{T}$ lymphocyte function both at the stage of blastic transformation and cytolysis [35-40]. Increased adenosine concentration is partially responsible for severe combined immunodeficiency syndrome observed in patients with inherited adenosine deaminase deficiency. These immunosuppressive effects are of particular interest during transplantation. Adenosine also affects several processes involved in the pathogenic mechanisms of heart failure such as TNF $\alpha$ and IL6 production [41-44], apoptosis [45] and proliferation of fibroblasts and smooth muscle cells [46-50]. We have previously shown the significant capacity of human endothelial cells to degrade AMP via the deamination pathway [51]. An increased adenosine production in cardiac endothelial cells due to deficiency of AMPD is one possible mechanism of the cardioprotective effects. However, even changes in remote organs may equally exert beneficial cardiac effects. Preconditioning at a distance has been demonstrated, indicating that an increase in adenosine production outside the heart in skeletal muscle for example may exert beneficial cardiac effects [52]. It has been shown also that a period of brief myocardial ischemia and increased cardiac adenosine production are capable of attenuating platelet aggregation in remote arteries [53]. Treatment with A2 adenosine receptor agonists was found to exert beneficial effects in animal models of both acute and chronic heart failure [54].

Despite numerous reports indicating benefits of elevated adenosine in cardiovascular disease, caution is needed as some studies demonstrated deleterious effects. The AMISTAD trial reported reduced infarct size but increased number of adverse clinical events, including death, in patients infused with adenosine as an adjunct to thrombolysis [55]. The administration of adenosine could be proarrhythmic [56] or produce coronary artery steal phenomenon in patients with critical stenosis [57]. Besides cardiovascular effects adenosine can contribute to fluid-retaining disorders via its A1 receptor mediated effects in the kidney [58] or induce bronchospasm in some patients [59]. Adenosine effects on immune cell function mediated by purinergic receptors may also promote cancer progression [60]. While these deleterious effects are restricted to specific clinical scenarios, its careful monitoring is needed in any adenosine related therapy including potential treatment with AMPD inhibitors.

\section{Activation of AMP Regulated Protein Kinase by AMP Deaminase Inhibition}

AMP is not only a substrate for the AMPD reaction but also an allosteric regulator that signals energy deficiency in the cell. AMP directly activates glycolytic enzymes and indirectly controls a broad range of cellular functions via AMP regulated protein kinase (AMPK). AMPK is a heterotrimeric protein that was initially described as a regulator of energy metabolism [61, 62] but later found to play a role in cytoprotection, cell growth and regeneration [63]. The metabolic role of AMPK includes activation of fatty acid transport into the mitochondria-accomplished by phosphorylation and inhibition of acetyl CoA carboxylase - and reduction of malonyl-CoA concentration. AMPK activates glucose transport into the cell by translocation of GLUT-4 into the membrane and controls the expression of enzymes of energy metabolism by phosphorylation of HIF-1. Besides its metabolic effects, AMPK is linked with the Akt kinase pathway and induction of proteins involved in cytoprotection and regeneration. Activation of AMPK in heart infarction or heart failure is currently considered as a therapeutic target [64]. AMPK is also believed to be activated by commonly used drugs such as metformin [65]. However, AMPK's protective effects could be dependent on how and when it is activated [66]. Loss of regulatory feedback in AMPK due to mutation in its $\gamma 2$ subunit (PRKAG2) resulting in constitutively increased activity is known to cause myocardial glycogen storage disease and cardiomyopathy [67-69]. Our current hypothesis is that inhibition of AMPD will act to amplify the AMP accumulation in cells with disrupted energy metabolism. This indirect AMPK activation by its endogenous activator could be superior to direct activation of AMPK (e.g. by AICAr) since AMPK activation would be restricted to cells and conditions where this activation is necessary. We have in vitro evidence showing that high AMPD activity could suppress AMPK activity, possibly by competition for AMP. Recent study on the mechanism of AMPK activation by metformin has suggested involvement of inhibition of AMPD [70].

\section{Inhibition of AMP Deaminase as a Therapeutic Strategy}

We have developed several possible therapeutic strategies based on the beneficial effects of adenosine that are applicable during cardiac surgery. We have established that adenosine administration both as a constituent of cardioplegic solution or as an infusion following cardioplegic arrest is beneficial [71, 72]. Administration of adenosine at the time of cardioplegic arrest, after reperfusion or after myocardial infarction is undergoing clinical evaluation. We have also developed a procedure that allows endogenous adenosine production in normoxic cardiac cells to increase by combined application of adenosine metabolism inhibitors and substrates for nucleotide synthesis [73]. We have shown that application of this procedure following experimental transplantation resulted in an improvement in all aspects of cardiac mechanical function, roughly a threefold decrease in postischemic cardiac neutrophil infiltration and an increase in myocardial ATP concentration. The discovery that genetic alterations of nucleotide metabolism that potentially 
leads to enhanced adenosine production and result in improved clinical outcome in heart dysfunction indicates new areas where such treatment could be applied.

The limited availability of specific inhibitors of AMPD is a major drawback for testing the regulation of AMPD in heart disease. Such inhibitors are not commercially available, although a procedure for chemical synthesis has been described [74] and preliminary evaluation of their effects has been performed as part of a $\mathrm{PhD}$ thesis [75]. We have followed this procedure and chemically synthesized a most effective compound: 3-[2-(3-carboxy-4-bromo-5,6,7,8-tetrahydronaphthyl)ethyl]-3,6,7,8-tetrahydroimidazo[4,5-d][1,3]diazepin-8ol (AMPDI). We have performed several preliminary studies using AMPDI with isolated AMPD, with heart homogenates, in isolated rat cardiomyocytes, perfused hearts and in mice in vivo [76-78]. In each case the efficiency of AMPD inhibition was confirmed, although in cardiomyocytes, perfused hearts and in vivo the concentration of inhibitor had to be several orders of magnitude higher than for isolated enzyme or heart homogenate alone. We have established that even at these high concentrations AMPDI remained specific for AMPD inhibition. While further studies are necessary to clarify the difference in effective concentration we believe that we have optimized the conditions for in vivo use of AMPDI. We have conducted a preliminary assessment of AMPDI effects in a mouse model of cardiac hypoxia and have demonstrated a protective effect [78]. We have established that the half life of AMPDI in mouse blood is relatively short (about $30 \mathrm{~min}$ ) and that AMPD inhibition in vivo is transient, even with continuous infusion. AMPDI could therefore be a good tool to study the acute effects of AMPD inhibition, but the design of chemicals suitable for long term in vivo use and as drug candidates requires further work.

\begin{abstract}
Acknowledgments This work was supported by the European Union from the resources of the European Regional Development Fund under the Innovative Economy Programme (grant coordinated by JCET-UJ, No. POIG.01.01.02-00-06) and TEAM program of Foundation for Polish Science (TEAM/2011-8/7). PB is supported by the National Institute for Health Research Cardiovascular BRU at the Brompton and Harefield NHS Foundation Trust and Imperial College London.
\end{abstract}

Open Access This article is distributed under the terms of the Creative Commons Attribution License which permits any use, distribution, and reproduction in any medium, provided the original author(s) and the source are credited.

\section{References}

1. Binkley PF, Auseon A, Cooke G. A polymorphism of the gene encoding AMPD1: clinical impact and proposed mechanisms in congestive heart failure. Congest Heart Fail. 2004;10:274-8.

2. Safranow K, Suchy J, Jakubowska K, Olszewska M, Binczak-Kuleta A, Kurzawski G, et al. AMPD1 gene mutations are associated with obesity and diabetes in Polish patients with cardiovascular diseases. $\mathrm{J}$ Appl Genet. 2011;52:67-76.
3. Toyama K, Morisaki H, Kitamura Y, Gross M, Tamura T, Nakahori $\mathrm{Y}$, et al. Haplotype analysis of human AMPD1 gene: origin of common mutant allele. J Med Genet. 2004;41:e74.

4. Loh E, Rebbeck TR, Mahoney PD, DeNofrio D, Swain JL, Holmes EW. Common variant in AMPD1 gene predicts improved clinical outcome in patients with heart failure. Circulation. 1999;99:1422-5.

5. Anderson JL, Habashi J, Carlquist JF, Muhlestein JB, Horne BD, Bair TL, et al. A common variant of the AMPD1 gene predicts improved cardiovascular survival in patients with coronary artery disease. J Am Coll Cardiol. 2000;36:1248-52.

6. Gastmann A, Sigusch HH, Henke A, Reinhardt D, Surber R, Gastmann O, et al. Role of adenosine monophosphate deaminase-1 gene polymorphism in patients with congestive heart failure (influence on tumor necrosis factor-alpha level and outcome). Am J Cardiol. 2004;93:1260-4.

7. Yazaki Y, Muhlestein JB, Carlquist JF, Bair TL, Horne BD, Renlund DG, et al. A common variant of the AMPD1 gene predicts improved survival in patients with ischemic left ventricular dysfunction. J Card Fail. 2004;10:316-20.

8. Agewall S, Norman B. Association between AMPD1 gene polymorphism and coagulation factors in patients with coronary heart disease. Pathophysiol Haemost Thromb. 2006;35:440-4.

9. Collins RP, Palmer BR, Pilbrow AP, Frampton CM, Troughton RW, Yandle TG, et al. Evaluation of AMPD1 C34T genotype as a predictor of mortality in heart failure and post-myocardial infarction patients. Am Heart J. 2006;152:312-20.

10. de Groote P, Lamblin N, Helbecque N, Mouquet F, Hermant X, Amouyel $\mathrm{P}$, et al. The impact of the AMPD1 gene polymorphism on exercise capacity, other prognostic parameters, and survival in patients with stable congestive heart failure: a study in 686 consecutive patients. Am Heart J. 2006;152:736-41.

11. Andreassi MG, Botto N, Laghi-Pasini F, Manfredi S, Ghelarducci B, Farneti A, et al. AMPD1 (C34T) polymorphism and clinical outcomes in patients undergoing myocardial revascularization. Int $\mathrm{J}$ Cardiol. 2005;101:191-5.

12. Fischer H, Esbjornsson M, Sabina RL, Stromberg A, Peyrard-Janvid M, Norman B. AMP deaminase deficiency is associated with lower sprint cycling performance in healthy subjects. J Appl Physiol. 2007;103:315-22.

13. Yacoub MH, Yuen AH, Kalsi KK, Birks EJ, Taegtmeyer A, Barton PJ, et al. C34T AMP deaminase 1 gene mutation protects cardiac function in donors. Transplantation. 2004;77:1621-3.

14. Yuen AH, Yacoub MH, Birks EJ, Kalsi KK, Johnson PH, Smolenski RT. Association of improved cardiac function in donors with C34T mutation of the AMP deaminase 1 gene. Nucleosides Nucleotides Nucleic Acids. 2005;24:275-7.

15. Taegtmeyer AB, Breen JB, Rogers P, Johnson PH, Smith J, Smolenski RT, et al. Effect of adenosine monophosphate deaminase-1 C34T allele on the requirement for donor inotropic support and on the incidence of early graft dysfunction after cardiac transplantation. Am J Cardiol. 2009;103:1457-62.

16. Smolenski RT, Borkowski T, Lewicki L, Al-Ayoubi S, Slominska EM, Lango R, et al. Cardioprotective effect of AMP deaminase inhibition in oxygen deprivation. Circulation. 2010;122, A19495.

17. Morisaki H, Morisaki T, Newby LK, Holmes EW. Alternative splicing: a mechanism for phenotypic rescue of a common inherited defect. J Clin Invest. 1993;91:2275-80.

18. Morisaki T, Gross M, Morisaki H, Pongratz D, Zollner N, Holmes EW. Molecular basis of AMP deaminase deficiency in skeletal muscle. Proc Natl Acad Sci U S A. 1992;89:6457-61.

19. Morisaki H, Morisaki T, Kariko K, Genetta T, Holmes EW. Positive and negative elements mediate control of alternative splicing in the AMPD1 gene. Gene. 2000;246:365-72.

20. Morisaki T, Sermsuvitayawong K, Wang X, Nagabukuro A, Matsuda Y, Ogasawara N, et al. Molecular analysis of mouse Ampd3 gene 
encoding heart-type isoform of AMP deaminase. Adv Exp Med Biol. 1998;431:337-40

21. Kalsi KK, Yuen AH, Johnson PH, Birks EJ, Yacoub MH, Smolenski RT. AMPD1 C34T mutation selectively affects AMP-deaminase activity in the human heart. Nucleosides Nucleotides Nucleic Acids. 2005;24:287-8.

22. Kalsi KK, Yuen AH, Rybakowska IM, Johnson PH, Slominska E, Birks EJ, et al. Decreased cardiac activity of AMP deaminase in subjects with the AMPD1 mutation-A potential mechanism of protection in heart failure. Cardiovasc Res. 2003;59:678-84.

23. Smolenski RT, Suitters A, Yacoub MH. Adenine nucleotide catabolism and adenosine formation in isolated human cardiomyocytes. $\mathrm{J}$ Mol Cell Cardiol. 1992;24:91-6.

24. Smolenski RT, Schrader J, de Groot H, Deussen A. Oxygen partial pressure and free intracellular adenosine of isolated cardiomyocytes. Am J Physiol. 1991;260:C708-14.

25. Norman B, Sabina RL, Jansson E. Regulation of skeletal muscle ATP catabolism by AMPD1 genotype during sprint exercise in asymptomatic subjects. J Appl Physiol. 2001;91:258-64.

26. Sabina RL, Swain JL, Olanow CW, Bradley WG, Fishbein WN, DiMauro S, et al. Myoadenylate deaminase deficiency. Functional and metabolic abnormalities associated with disruption of the purine nucleotide cycle. J Clin Invest. 1984;73:720-30.

27. Smolenski RT, Raisky O, Slominska EM, Abunasra H, Kalsi KK, Jayakumar J, et al. Protection from reperfusion injury after cardiac transplantation by inhibition of adenosine metabolism and nucleotide precursor supply. Circulation. 2001;104:I246-52.

28. Berne RM. The role of adenosine in the regulation of coronary blood flow. Circ Res. 1980;47:807-13.

29. Newby AC. Adenosine and the concept of retaliatory metabolites. Trends Biochem Sci. 1984;9:42-4.

30. Grisham MB, Hernandez LA, Granger DN. Adenosine inhibits ischemia-reperfusion-induced leukocyte adherence and extravasation. Am J Physiol. 1989;257:H1334-9.

31. Grover GJ, Sleph PG, Dzwonczyk S. Role of myocardial ATPsensitive potassium channels in mediating preconditioning in the dog heart and their possible interaction with adenosine A1receptors. Circulation. 1992;86:1310-6.

32. Gunther GR, Herring MB. Inhibition of neutrophil superoxide production by adenosine released from vascular endothelial cells. Ann Vasc Surg. 1991;5:325-30.

33. Mills DCB, MacFarlane DE, Lemmex BWG, Haslam RJ. Receptors for nucleosides and nucleotides on blood platelets. In: Berne RM, Rall TW, Rubio R, editors. Regulatory functions of adenosine. The Hague: Nijhof Publs; 1983. p. 277-89.

34. Schrader J, Baumann G, Gerlach E. Adenosine as inhibitor of myocardial effects of catecholamines. Pflugers Arch. 1977;372:29-35.

35. Carrera CJ, Saven A, Piro LD. Purine metabolism of lymphocytes. Targets for chemotherapy drug development. Hematol Oncol Clin N Am. 1994;8:357-81.

36. Gordon AS, Diamond I. Adenosine mediates the effects of ethanol on the cAMP signal transduction system. Alcohol Alcohol Suppl. 1993;2:437-41.

37. Hoskin DW, Butler JJ, Drapeau D, Haeryfar SM, Blay J. Adenosine acts through an $\mathrm{A} 3$ receptor to prevent the induction of murine antiCD3-activated killer T cells. Int J Cancer. 2002;99:386-95.

38. Hoskin DW, Reynolds T, Blay J. Adenosine as a possible inhibitor of killer T-cell activation in the microenvironment of solid tumours [letter]. Int J Cancer. 1994;59:854-5.

39. Szondy Z. Adenosine stimulates DNA fragmentation in human thymocytes by $\mathrm{Ca}(2+)$-mediated mechanisms. Biochem J. 1994;304:877-85.

40. Wolberg G, Zimmerman TP, Duncan GS, Kay H, Elion G. Inhibition of lymphocyte mediated cytolysis by adenosine analogues: biochemical studies concerning mechanism of action. Biochem Pharmacol. 1978;27:1487-95.
41. Bullough DA, Magill MJ, Firestein GS, Mullane KM. Adenosine activates A2 receptors to inhibit neutrophil adhesion and injury to isolated cardiac myocytes. J Immunol. 1995;155:2579-86.

42. Meldrum DR, Cain BS, Cleveland Jr JC, Meng X, Ayala A, Banerjee A, et al. Adenosine decreases post-ischaemic cardiac TNF-alpha production: anti- inflammatory implications for preconditioning and transplantation. Immunology. 1997;92:472-7.

43. Meldrum DR, Dinarello CA, Shames BD, Cleveland Jr JC, Cain BS, Banerjee A, et al. Ischemic preconditioning decreases postischemic myocardial tumor necrosis factor-alpha production. Potential ultimate effector mechanism of preconditioning. Circulation. 1998;98:II214 8. discussion II218-.

44. Wagner DR, Kubota T, Sanders VJ, McTiernan CF, Feldman AM. Differential regulation of cardiac expression of IL-6 and TNF-alpha by A2- and A3-adenosine receptors. Am J Physiol. 1999;276: H2141-7.

45. Rounds S, Yee WL, Dawicki DD, Harrington E, Parks N, Cutaia MV. Mechanism of extracellular ATP- and adenosine-induced apoptosis of cultured pulmonary artery endothelial cells. Am J Physiol. 1998;275:L379-88.

46. Colquhoun A, Newsholme EA. Inhibition of human tumour cell proliferation by analogues of adenosine. Cell Biochem Funct. 1997; 15:135-9.

47. Dubey RK, Gillespie DG, Mi Z, Jackson EK. Exogenous and endogenous adenosine inhibits fetal calf serum-induced growth of rat cardiac fibroblasts. Role of A2B receptors. Circulation. 1997;96: 2656-66.

48. Lelievre V, Muller JM, Falcon J. Adenosine modulates cell proliferation in human colonic adenocarcinoma. I. Possible involvement of adenosine A1 receptor subtypes in HT29 cells. Eur J Pharmacol. 1998;341:289-97.

49. Pares-Herbute N, Hillaire-Buys D, Etienne P, Gross R, LoubatieresMariani MM, Monnier L. Adenosine inhibitory effect on enhanced growth of aortic smooth muscle cells from streptozotocin-induced diabetic rats. Br J Pharmacol. 1996;118:783-9.

50. Vainio M, Saarinen P, Tornquist K. Adenosine inhibits DNA synthesis stimulated with TSH, insulin, and phorbol 12-myristate 13-acetate in rat thyroid FRTL-5 cells. J Cell Physiol. 1997;171:336-42.

51. Smolenski RT, Kochan Z, McDouall R, Page C, Seymour A-ML, Yacoub MH. Endothelial nucleotide catabolism and adenosine production. Cardiovasc Res. 1994;28:100-4.

52. Pell TJ, Baxter GF, Yellon DM, Drew GM. Renal ischemia preconditions myocardium: role of adenosine receptors and ATP-sensitive potassium channels. Am J Physiol. 1998;275:H1542-7.

53. Hata K, Whittaker P, Kloner RA, Przyklenk K. Brief myocardial ischemia attenuates platelet thrombosis in remote, damaged, and stenotic carotid arteries. Circulation. 1999;100:843-8.

54. Nekooeian AA, Tabrizchi R. Haemodynamic effects of a selective adenosine A2A receptor agonist, CGS 21680, in chronic heart failure in anaesthetized rats. Br J Pharmacol. 1998;125:651-8.

55. Mahaffey KW, Puma JA, Barbagelata NA, DiCarli MF, Leesar MA, Browne KF, et al. Adenosine as an adjunct to thrombolytic therapy for acute myocardial infarction: results of a multicenter, randomized, placebo-controlled trial: the Acute Myocardial Infarction STudy of ADenosine (AMISTAD) trial. J Am Coll Cardiol. 1999;34:1711-20.

56. Camaiti A, Pieralli F, Olivotto I, Grifoni S, Conti A, Del RA, et al. Prospective evaluation of adenosine-induced proarrhythmia in the emergency room. Eur J Emerg Med. 2001;8:99-105.

57. Mullane K, Bullough D. Harnessing an endogenous cardioprotective mechanism: cellular sources and sites of action of adenosine. J Mol Cell Cardiol. 1995;27:1041-54.

58. Modlinger PS, Welch WJ. Adenosine A1 receptor antagonists and the kidney. Curr Opin Nephrol Hypertens. 2003;12:497-502.

59. Drake I, Routledge PA, Richards R. Bronchospasm induced by intravenous adenosine. Hum Exp Toxicol. 1994;13:263-5. 
60. Kumar V. Adenosine as an endogenous immunoregulator in cancer pathogenesis: where to go? Purinergic Signal. 2013;9:145-65.

61. Hardie DG. AMP-activated protein kinase as a drug target. Annu Rev Pharmacol Toxicol. 2007;47:185-210.

62. Hardie DG. AMPK: a key regulator of energy balance in the single cell and the whole organism. Int J Obes (Lond). 2008;32 Suppl 4:S7-S12.

63. Carling D. The AMP-activated protein kinase cascade-a unifying system for energy control. Trends Biochem Sci. 2004;29:18-24.

64. Zaha VG, Young LH. AMP-activated protein kinase regulation and biological actions in the heart. Circ Res. 2012;111:800-14.

65. Whittington HJ, Hall AR, McLaughlin CP, Hausenloy DJ, Yellon DM, Mocanu MM. Chronic metformin associated cardioprotection against infarction: not just a glucose lowering phenomenon. Cardiovasc Drugs Ther. 2013;27:5-16.

66. Kim M, Tian R. Targeting AMPK for cardiac protection: opportunities and challenges. J Mol Cell Cardiol. 2011;51:548-53.

67. Akman HO, Sampayo JN, Ross FA, Scott JW, Wilson G, Benson L, et al. Fatal infantile cardiac glycogenosis with phosphorylase kinase deficiency and a mutation in the gamma2-subunit of AMP-activated protein kinase. Pediatr Res. 2007;62:499-504.

68. Dyck JR, Lopaschuk GD. AMPK alterations in cardiac physiology and pathology: enemy or ally? J Physiol. 2006;574:95-112.

69. Burwinkel B, Scott JW, Buhrer C, van Landeghem FK, Cox GF, Wilson CJ, et al. Fatal congenital heart glycogenosis caused by a recurrent activating R531Q mutation in the gamma 2-subunit of AMP-activated protein kinase (PRKAG2), not by phosphorylase kinase deficiency. Am J Hum Genet. 2005;76:1034-49.

70. Ouyang J, Parakhia RA, Ochs RS. Metformin activates AMPkinase through inhibition of AMP deaminase. J Biol Chem. 2010;286: $1-11$.
71. Katayama O, Ledingham SJM, Amrani M, Smolenski RT, Lachno DR, Jayakumar J, et al. Functional and metabolic effects of adenosine in cardioplegia: role of temperature and concentration. Ann Thorac Surg. 1997;63:449-55.

72. Ledingham S, Katayama O, Lachno D, Patel N, Yacoub M. Beneficial effect of adenosine during reperfusion following prolonged cardioplegic arrest. Cardiovasc Res. 1990;24:247-53.

73. Smolenski RT, Kalsi KK, Zych M, Kochan Z, Yacoub MH. Adenine/ ribose supply increases adenosine production and protects ATP pool in adenosine kinase inhibited cardiac cells. J Mol Cell Cardiol. 1998;30:673-83.

74. Kasibhatla SR, Bookser BC, Xiao W, Erion MD. AMP deaminase inhibitors. 5. Design, synthesis, and SAR of a highly potent inhibitor series. J Med Chem. 2001;44:613-8.

75. Se-Chan K. Die Umsatzrate der AMP-Desaminase im Meerschweinchenherzen. Thesis, Der Medizinischen Fakultät der Heinrich-Heine-Universität Düsseldorf; 2003.

76. Borkowski T, Slominska EM, Orlewska C, Yuen AH, Al-Ayoubi S, Siondalski P, et al. Biological efficiency of AMP deaminase inhibitor: 3-[2-(3-carboxy-4-bromo-5,6,7,8-tetrahydronaphthyl)ethyl]-3,6,7,8tetrahyd roimidazo[4,5]-[1,3]diazepin-8-OL. Nucleosides Nucleotides Nucleic Acids. 2010;29:457-60.

77. Borkowski T, Orlewska C, Slominska EM, Yuen A, Lipinski M, Rybakowska I, et al. Pharmacological inhibition of AMP-deaminase in rat cardiac myocytes. Nucleosides Nucleotides Nucleic Acids. 2008;27:867-71.

78. Borkowski T, Slominska EM, Orlewska C, Chlopicki S, Siondalski P, Yacoub MH, et al. Protection of mouse heart against hypoxic damage by AMP deaminase inhibition. Nucleosides Nucleotides Nucleic Acids. 2010;29:449-52. 